CLINICAL STUDY

\title{
Evaluation of the sensitivity to chemotherapeutics or thiazolidinediones of primary anaplastic thyroid cancer cells obtained by fine-needle aspiration
}

Alessandro Antonelli, Silvia Martina Ferrari, Poupak Fallahi, Piero Berti ${ }^{1}$, Gabriele Materazzi ${ }^{1}$, Ivo Marchetti ${ }^{2}$, Clara Ugolini ${ }^{1}$, Fulvio Basolo ${ }^{1}$, Paolo Miccoli ${ }^{1}$ and Ele Ferrannini

Department of Internal Medicine, School of Medicine, University of Pisa, Via Roma, 67, I-56100 Pisa, Italy, ${ }^{1}$ Department of Surgery, University of Pisa, Pisa, Italy and ${ }^{2}$ Division of Surgical, Molecular and Ultrastructural Pathology, Section of Cytopathology, University Hospital of Pisa, Pisa, Italy

(Correspondence should be addressed to A Antonelli; Email: a.antonelli@med.unipi.it)

\begin{abstract}
Objective: Anaplastic thyroid cancer (ATC) is often unoperable and chemotherapy and radiotherapy are the main treatments. Until now 'primary ATC cell cultures' (ANA) have been developed from surgical biopsies. The possibility to obtain ANA from fine-needle aspiration (FNA-ANA) and to test their sensitivity to different drugs could increase the effectiveness of treatments and avoid unnecessary surgical procedures.

Design: To obtain FNA-ANA from six ATC patients before undergoing surgery and to evaluate the chemosensitivity of FNA-ANA to chemotherapeutic agents and thiazolidinediones (TZD).

Methods and results: FNA-ANA from the six ATC patients were cultured in RPMI 1640 and propagated in DMEM. Chemosensitivity was evaluated by inhibiting the proliferation with increasing concentrations of five different chemotherapeutic agents (bleomycin, cisplatin, gemcitabine, etoposide, and carboplatin) or TZD (rosiglitazone). Chemotherapeutic agents significantly inhibited $(P<0.0001)$ FNA-ANA proliferation, such as TZD $(P<0.001)$; etoposide was the most effective in reducing cell growth. Another ANA culture for each patient was obtained from a biopsy specimen; the results for the chemosensitivity tests were similar to those obtained with FNA-ANA. The ${ }^{\mathrm{V} 600 \mathrm{E}}$ BRAF mutation was observed in two ATC patients; the inhibition of proliferation by drugs was similar in tumors with or without ${ }^{\mathrm{V} 600 \mathrm{E}}$ BRAF mutation.

Conclusions: Our study demonstrates 1) the possibility to obtain FNA-ANA, and opens the way to the use of FNA-ANA to test the chemosensitivity to different drugs (chemotherapeutic agents or TZD; and possibly the radiosensitivity) in each patient, avoiding unnecessary surgical procedures and the administration of inactive chemotherapeutics; and 2) that etoposide is highly effective in reducing ATC cell growth in vitro.
\end{abstract}

European Journal of Endocrinology 159 283-291

\section{Introduction}

The medical treatment of patients with anaplastic thyroid cancer (ATC) has still not been well defined. Some experts advocate aggressive multimodal treatment (surgery, chemotherapy (CT), radiotherapy) for ATC. In some studies, patients treated with total thyroidectomy, followed by radiotherapy and CT (1-3), survived longer than the other patients; but these results have not been confirmed by other authors (4-6).

Disease orientated in vitro drug screening using human tumor cell lines has some predictive value for the activity of clinical responses $(7,8)$. A positive predictive value has been reported for in vitro drug screening of $\sim 60 \%$ of patients and a negative predictive value of $90 \%$ (9). Thus, in vitro drug screening might help to prevent the administration of inactive chemotherapeutics to patients. Based on this model, the potential activity of gemcitabine (10), vinorelbine, and paclitaxel $(11,12)$ has been recently reported in ATC. These studies underline the potential value of preclinical drug screening.

The most recent development in the treatment of ATC seems to be represented by the possibility offered by peroxisome proliferator-activated receptor $-\gamma(\operatorname{PPAR} \gamma)$ agonists, by adenovirus-mediated $p 53$ tumor suppressor gene therapy or by the use of vascular and growth factor-targeted agents (13). All these new therapies need further confirmation coming from ongoing in vitro studies and clinical trials.

In particular, newly developed synthetic PPAR $\gamma$ agonists include anti-diabetic drugs, thiazolidinediones (TZD) (troglitazone, rosiglitazone, pioglitazone, etc.) (14), that elicit both anti-neoplastic (14) and antiinflammatory effects (15) in several types of mammalian cells. Recently, it has been shown that TZD exert 
anti-proliferative effects on human papillary carcinoma cells (16), and it has been proposed that PPAR $\gamma$ agonists may be effective for the treatment of patients with thyroid cancer that fails to respond to traditional treatments (17-20). Moreover, it has been shown that TZD inhibited cell proliferation and down-regulated the invasive potential in five continuous human anaplastic cancer cell lines (21). These results have been recently confirmed by other studies (19).

The possibility to test the sensitivity of "primary ATC cell' (ANA) cultures from each subject to different drugs could permit an increase in the effectiveness of the treatment. Until now, primary ANA cultures have been obtained from surgical biopsies (biopsy-ANA) performed for therapeutic or diagnostic procedures. The possibility to develop primary ANA cultures from fine-needle aspiration (FNA) could avoid unnecessary surgical procedures and allow the sensitivity to different chemotherapeutics to be evaluated in each patient.

Here, we report the establishment of ANA cultures from cells obtained by FNA cytology, and the results of chemosensitivity tests with chemotherapeutic agents or PPAR $\gamma$ agonists TZD.

\section{Subjects and methods}

\section{Patients source for thyroid tissue}

FNA samples were obtained from six patients with ATC by FNA cytology (23 gauge needle). Surgical thyroid tissue was obtained from the same six patients with ATC (the tissue was obtained from a thyroid biopsy during first surgical operation). The diagnosis was established on commonly accepted clinical, laboratory, and histological criteria (22). Immunohistochemistry showed the absence of expression of thyrotropin (TSH) receptor, thyroperoxidase (TPO), thyroglobulin (Tg) and sodium/ iodide symporter (NIS).

The study subjects gave their informed consent to the study, which was approved by the Ethical Committee of the University of Pisa.

\section{Microdissection and DNA extraction}

Serial $5 \mu \mathrm{m}$ sections were taken from paraffin blocks for histological examination on glass slides and for DNA extraction on membrane slides (Nikon, Firenze, Italy). The presence of the tumor tissue was confirmed in the first and the last section for each section series. Unstained sections were deparaffinized with Bio-Clear (Bio-optica, Milano, Italy), rehydrated in graded ethanol, and stained with H\&E. Microdissections were performed using the laser-assisted SL microcut Microtest (MMI GmbH distributed by Nikon). For each sample, 3-5 microareas of $5 \mu \mathrm{m}$ were obtained. Each area contained 200-500 cells. Particular care was taken in microdissecting areas of the tumor. Samples from the non-neoplastic thyroid parenchyma, generally from the contralateral lobe, were dissected as control reference. The microdissected cells were placed in the SL microcut transfer film (Nikon) and the DNA was extracted overnight in a humidified chamber at $56^{\circ} \mathrm{C}$ in $200 \mu \mathrm{l}$ tissue lysis buffer (ATL DNeasy Tissue kit; Qiagen $\mathrm{GmbH}$ ) containing $20 \mu \mathrm{l}$ proteinase K. DNA was isolated by Qiagen spin column; carrier tRNA was added to improve DNA recovery. Finally, DNA was eluted in $40 \mathrm{mcl}$ TE buffer and immediately processed for PCR amplification. A mock control, in which no tissue was added, was processed in parallel with each sample (23).

\section{Detection of BRAF mutation by PCR-SSCP and direct DNA sequencing}

PCR-SSCP screening of BRAF mutations was performed by amplifying exon 15 according to a standard procedure (24). DNA was used as a template in a $20 \mu \mathrm{l}$ PCR mixture containing $10 \mathrm{mM}$ Tris- $\mathrm{HCl}, 50 \mathrm{mM}$ $\mathrm{KCl}, 1.5 \mathrm{mM} \mathrm{MgCl}_{2}$ (pH 8.3), 0.2 mM dNTPs, 8 pmol amplimers, and 1.25 U AmpliTaq Gold DNA Polymerase (Applied Biosystems, Foster City, CA, USA). PCR primers for the BRAF exon 15 were as follows: $5^{\prime}(\mathrm{F})$ TCCTTTACTTACTACACCTCAGAT-3' and $5^{\prime}(\mathrm{R})$-AGTGGAAAAATAGCCTCAAT-3'.

The amplicon size was $167 \mathrm{bp}$. Cycling conditions were as follows: initial denaturation $\left(94^{\circ} \mathrm{C}, 5 \mathrm{~min}\right)$, then 35 cycles (denaturation, $94^{\circ} \mathrm{C}$ for $40 \mathrm{~s}$; annealing, $55^{\circ} \mathrm{C}$ for $40 \mathrm{~s}$; synthesis, $72{ }^{\circ} \mathrm{C}$ for $40 \mathrm{~s}$ ), followed by a final extension of $5 \mathrm{~min}$ at $72{ }^{\circ} \mathrm{C}$. All PCR products were visualized by electrophoresis in $2 \% \mathrm{w} / \mathrm{v}$ agarose gel and purified using PCR purification kit (Qiagen). Purified products were then diluted 1:1 with denaturing solution $(1 \% \mathrm{v} / \mathrm{v}$ xylene cyanol, $1 \% \mathrm{v} / \mathrm{v}$ bromophenol blue, $0.1 \mathrm{mM}$ EDTA, and $99 \% \mathrm{v} / \mathrm{v}$ formamide), boiled for $5 \mathrm{~min}$ and immediately placed in ice to prevent the annealing of single-strand products. SSCP screening was carried out on the GenePhor Electrophoresis Unit using GeneGel Excel 12.5/24 (12.5\% T, 2\% C), according to the manufacturer's instructions (GE Healthcare, Milano, Italy). Electrophoresis $(600 \mathrm{~V}$, $25 \mathrm{~mA}, 15 \mathrm{~W}$ ) was performed at $18{ }^{\circ} \mathrm{C}$ for $100 \mathrm{~min}$. Gels were stained with PlusOne Silver Staining Kit (GE Healthcare), according to the manufacturer's instructions. Altered migration patterns in two or three independent PCR-SSCP runs were indicative of DNA mutations. Purified PCR products were then sequenced by an ALF II automated sequencer (GE Healthcare) using the Thermo Sequenase Cy 5 Dye Terminator Cycle Sequencing Kit (GE Healthcare). DNA sequences were compared with those of the normal BRAF gene exon 15 using the Basic Alignment Search Tool software (BLAST) available at www.ncbi.nlm.nih.gov/BLAST/. As a control, two human thyroid cancer cell lines, ARO and TPC, heterozygous and negative for the BRAF mutation respectively, were used (24). 


\section{ATC cell culture}

FNA samples were obtained from six patients with ATC by FNA cytology (23 gauge needle). FNA materials were spread out in a sterile environment (about 10000 cells were seeded) in six-well plates and cultured in RPMI 1640 (Sigma-Aldrich) containing gentamicin (20 $\mu \mathrm{g} / \mathrm{ml}$; Sigma-Aldrich), penicillin G (100 IU/ml; Sigma-Aldrich), glutamine (1\% w/v; Sigma-Aldrich), and FCS (20\% v/v; Seromed, Biochrom). After 2 weeks, cells were trypsinized and propagated in $75 \mathrm{~cm}^{2}$ flasks in DMEM (Sigma-Aldrich) containing penicillin/streptomycin $(50 \mathrm{mcg} / \mathrm{ml}$; Sigma-Aldrich), glutamine $(1 \%$ w/v; Sigma-Aldrich), and FCS (20\% v/v; Seromed, Biochrom), and then incubated at $37^{\circ} \mathrm{C}$ in $5 \% \mathrm{CO}_{2}$. Cells were used for chemosensitivity tests at the fourth passage, after 4-5 weeks of controlled in vitro growth in order to obtain an adequate number of cells.

Neoplastic tissue was finely minced into 1 to $3 \mathrm{~mm}$ pieces with a scalpel or scissors. Fragments were washed three to five times in M-199 media (Sigma-Aldrich) supplemented with penicillin (500 IU/ml; SigmaAldrich), streptomycin (500 IU/ml; Sigma-Aldrich), and nystatin (1000 IU/ml; Sigma-Aldrich). Tumor tissues were suspended in DMEM containing penicillin/streptomycin ( $50 \mathrm{mcg} / \mathrm{ml}$; Sigma-Aldrich), glutamine (1\% w/v; Sigma-Aldrich), and FCS (20\% v/v; Seromed, Biochrom), and incubated at $37^{\circ} \mathrm{C}$ in $5 \% \mathrm{CO}_{2}$.

Primary cultures reached confluence. Thereafter, the cells were detached with a trypsin solution and transferred to primary tissue-culture flasks (Becton Dickinson Labware, Bedford, MA, USA). At passage 3, cells were coated in methocel (25) to evaluate the colonyforming efficiencies. The biggest colonies were picked up and expanded in tissue-culture flasks. Cells were used for chemosensitivity tests at the fourth passage.

Immunohistochemistry showed the absence of expression of TSH receptor, TPO, Tg, and NIS. The presence of cytokeratin was investigated by immunocytochemistry on destained smears in FNA-ANA cells and a partial and focal positivity was obtained.

\section{Cell viability test}

A viability and proliferation assay was used by analyzing the number of viable cells by the cleavage of tetrazolium salts added to the culture medium (Cell Proliferation Reagent WST-1; Roche) (26). Proliferation assays have become available to analyze the number of viable cells by the cleavage of tetrazolium salts added to the culture medium. The tetrazolium salts are cleaved to formazan by cellular enzymes. An expansion in the number of viable cells results in an increase in the overall activity of mitochondrial dehydrogenases in the sample. This augmentation in enzyme activity leads to an increase in the amount of formazan dye formed, which directly correlates to the number of metabolically active cells in the culture (26). The formazan dye produced by metabolically active cells was quantified by a scanning multiwell spectrophotometer (ELISA reader) by measuring the absorbance of the dye solution at $450 \mathrm{~nm}$. Cells were seeded in a 96-well microtiter plate at a concentration of 35000 cells $/ \mathrm{ml}$ in a final volume of $100 \mu \mathrm{l}$ per well, followed by a 48-h incubation period with chemotherapeutic agents or PPAR $\gamma$ activator, as mentioned above, in a humidified atmosphere $\left(37^{\circ} \mathrm{C}, 5 \% \mathrm{CO}_{2}\right)$. After the incubation period, $10 \mu \mathrm{l}$ of the Cell Proliferation Reagent WST-1 was added to $100 \mu \mathrm{l}$ culture medium in each well and the absorbance of the samples was measured at $450 \mathrm{~nm}$ against the control (the same cells without any treatment) using a microtiter plate (ELISA) reader. The same volume of culture medium and Cell Proliferation Reagent WST-1 (10 $\mu \mathrm{l}$ Cell Proliferation Reagent WST-1/100 $\mu$ culture medium) was added to one well, in order to use this background control (absorbance of culture medium plus WST-1 in the absence of cells) as a blank position for the ELISA reader.

The absorbance was measured again after 1 and $2 \mathrm{~h}$, from the start of tetrazolium reaction.

The measured absorbance of blank was subtracted from the control and treatments; the control was normalized to $100 \%$ for each assay and treatments were expressed as a percentage of the control.

The experiments were conducted in triplicate for each FNA. The mean percentage of inhibition of proliferation was calculated with respect to the control for each FNA. The results are the mean percentage with respect to the control in the six FNA.

\section{Proliferation assay: cell counting}

Since 3-(4,5-dimethyl-2-thiazolyl)-2,5-diphenyl-2Htetrazolium bromide (used in the MTT assay) measures mitochondrial cell activity and it has already been demonstrated that there is not always a direct relationship with cell number, the proliferation was evaluated using cell number counting $(27,28)$, as well.

Cells were seeded at a density of 13000 cells per well in 24-well tissue-culture plates in medium supplemented with $10 \% \mathrm{FBS} v / \mathrm{v}$ with or without the indicated factors (12). The medium was changed every other day. After $72 \mathrm{~h}$ in an atmosphere of $5 \% \mathrm{CO}_{2}-95 \%$ air at $37^{\circ} \mathrm{C}$, the cells were detached from plates by incubation with $500 \mathrm{ml}$ PBS containing $100 \mathrm{mg}$ trypsin and $1 \mathrm{mmol} / \mathrm{l}$ EDTA. The cells were counted using a hemocytometer.

\section{Treatment of human cells with chemothera- peutic agents}

Human cells were treated in standard culture media as above for $48 \mathrm{~h}$ with different drugs: bleomycin $(3.5 \mu \mathrm{M}$; Crinos IF, Villa Guardia, Como, Italy) (29), carboplatin (100 $\mu \mathrm{M}$; Sigma-Aldrich) (30), cisplatin (10 $\mu \mathrm{M}$; Sigma-Aldrich) (31), gemcitabine (50 $\mathrm{MM}$; Lilly) (32), 
and etoposide (10 $\mu \mathrm{M}$; Bristol-Myers Squibb spol. sro, Olivova, Praha, Czech Republic) (33), at concentrations equivalent to peak plasma levels achieved in vivo $(29,31-33)$.

\section{Treatment of human cells with PPAR $\gamma$ activator}

Human cells were treated in standard culture media as above for $48 \mathrm{~h}$ with PPAR $\gamma$ activator, BRL49653 (rosiglitazone; gift from SmithKline Beecham) (0, 0.1, $1,5,10,20,30,40 \mu \mathrm{M})(15)$.

\section{Results}

FNA-ANA and biopsy-ANA grew to reach the confluence and we were able to obtain a sufficient quantity of material to perform the chemosensitivity tests; the morphology of cells was quite similar in FNA-ANA and biopsy-ANA (Fig. 1).

FNA-ANA were sensitive to all chemotherapeutic agents (Fig. 2). The anti-proliferative effect of chemotherapeutic agents became apparent after a minimum of $24 \mathrm{~h}$ of incubation and increased with longer incubation times. Shorter exposure times $(10$ and $18 \mathrm{~h}) \mathrm{did}$ not show any anti-proliferative effect on all tested cells;

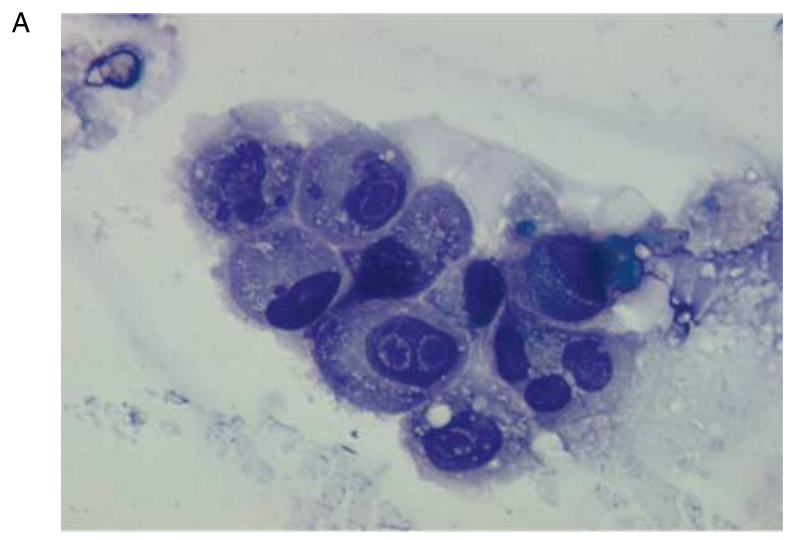

B

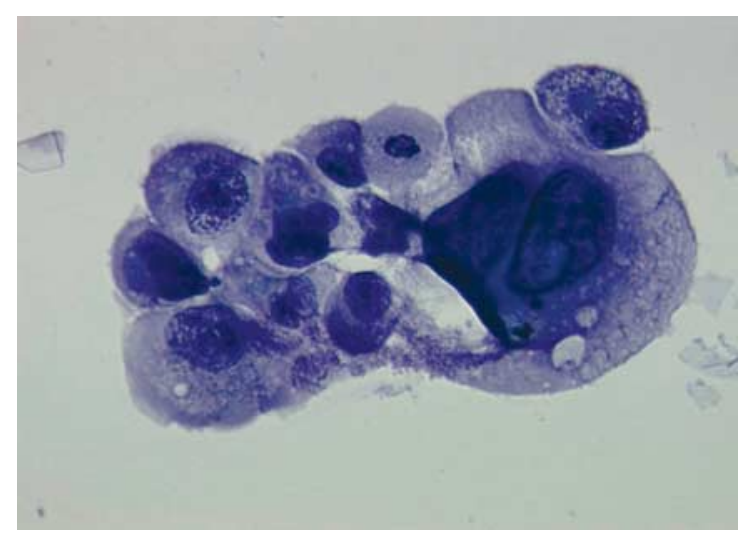

Figure 1 Anaplastic thyroid cancer cells cultured from (A) fine-needle aspiration cytology or (B) biopsy (Papanicolaou staining; $630 \times$ ).

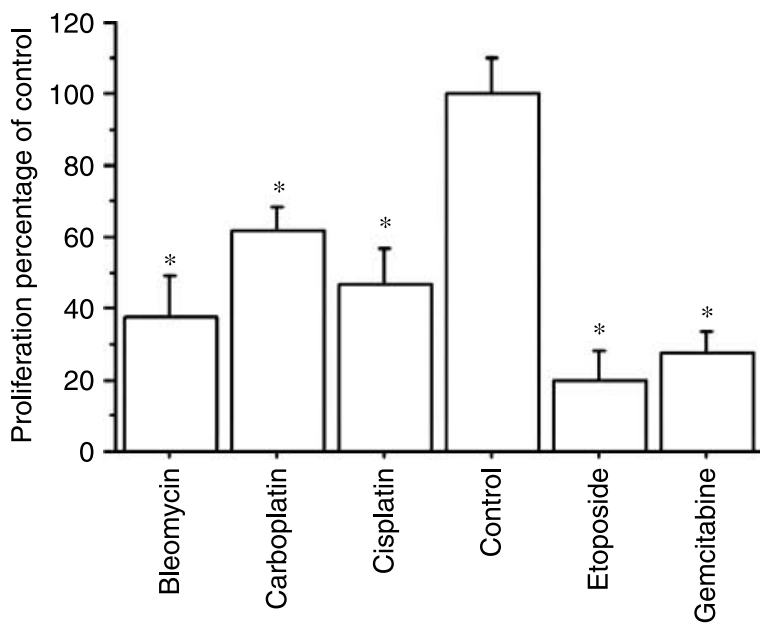

Figure 2 The results of WST-1 assay ( $2 \mathrm{~h}$ from the start of tetrazolium reaction) (mean \pm S.E.M. of all samples) in ANA cells from FNA showed a significant reduction $(P<0.001$, by ANOVA) of proliferation with respect to the control with all the tested chemotherapeutic agents (after $48 \mathrm{~h}$ of incubation).

therefore, results are not reported. The anti-proliferative effects were calculated after 2 days ( $48 \mathrm{~h}$ ) of incubation with chemotherapeutic agents. Gemcitabine and etoposide were significantly more effective in inhibiting the proliferation than carboplatin, cisplatin, and bleomycin $(P<0.05)$. The results of chemosensitivity tests in individual FNA-ANA are presented in Fig. 3. A similar trend for the sensitivity to each antiblastic was observed in individual FNA-ANA (the inhibition was higher with etoposide and gemcitabine), even if differences were present among the preparations (with a higher sensitivity in preparations 3B and 3F). No significant differences were observed between the sensitivity to antiblastics in FNA-ANA and biopsy-ANA from the same patient.

Cell counting confirmed the above-mentioned results in the whole group of FNA-ANA. In control FNA-ANA, the cell number was $39200 \pm 3200 / 100 \mathrm{mcl}$, per well; after the treatments, the cell number was: $13700 \pm$ 4000 (35\%, with respect to the control) with bleomycin; $26300 \pm 2350(67 \%)$ with carboplatin; $17270 \pm$ $3800(44 \%)$ with cisplatin; $9000 \pm 2450(23 \%)$ with etoposide; and $12100 \pm 1855$ (31\%) with gemcitabine $(P<0.001$, with respect to control, for all the tested drugs; ANOVA) (Fig. 4). Similar results were observed in biopsy-ANA cells.

The results for ANA cells cultured from biopsy were quite similar to those obtained from FNA-ANA (Fig. 5). Also in this case, gemcitabine and etoposide were significantly more effective in inhibiting the proliferation than cisplatin, bleomycin, and carboplatin $(P<0.05)$. There were no significant differences in sensitivity to chemotherapeutic agents between the tested cells from FNA cytology or biopsy.

The results of WST-1 assay in FNA-ANA after $48 \mathrm{~h}$ of incubation with rosiglitazone showed a reduction of 

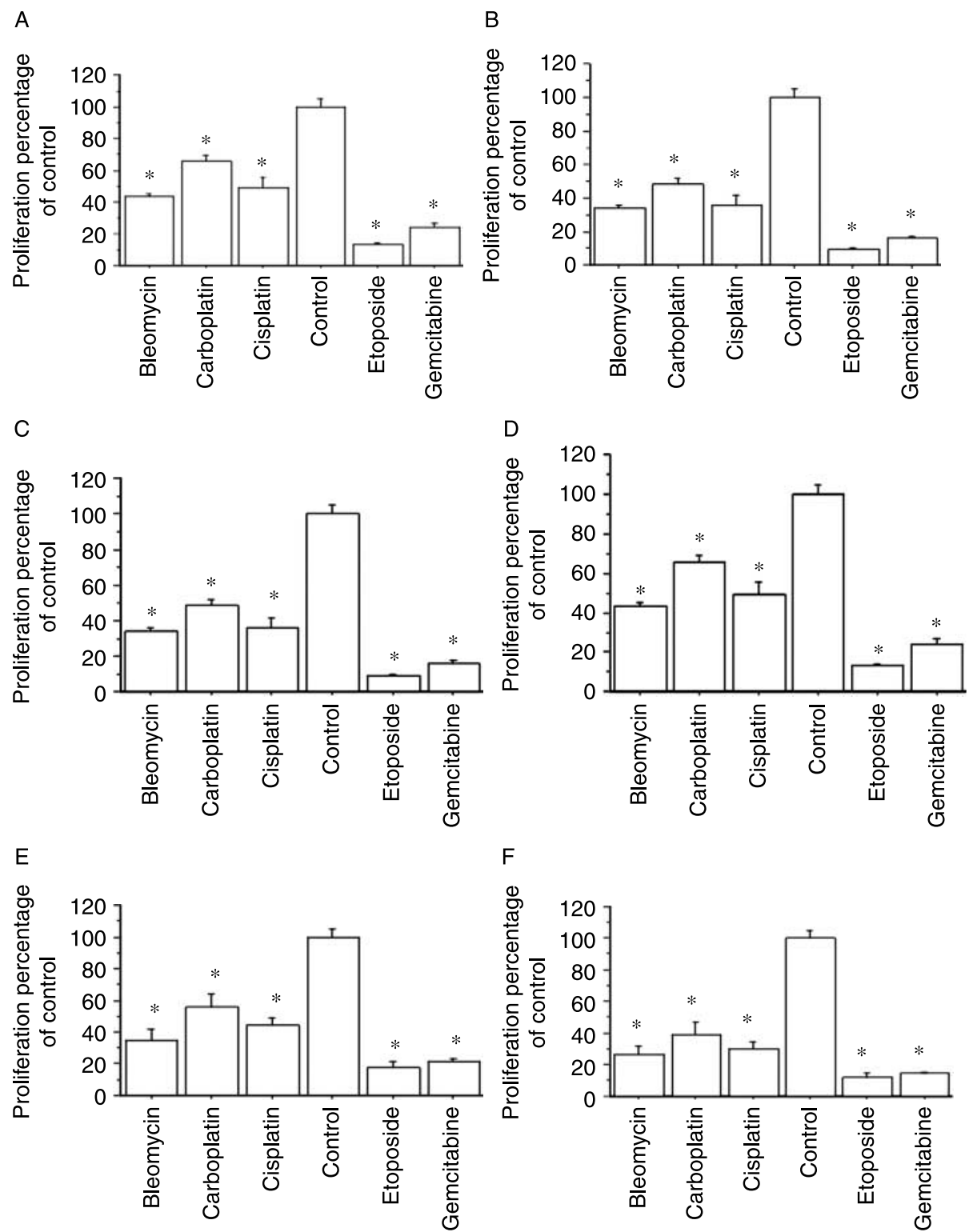

Figure $3(\mathrm{~A}-\mathrm{F})$ The results of WST-1 assay ( $2 \mathrm{~h}$ from the start of tetrazolium reaction) in ANA cells from each FNA showed a significant reduction $(P<0.001$, by ANOVA) of proliferation with respect to the control with all the tested chemotherapeutic agents (after $48 \mathrm{~h}$ of incubation). A similar trend for the sensitivity to each antiblastic was observed in individual FNA-ANA (the inhibition was higher with etoposide and gemcitabine), even if differences were present among the preparations (with a higher sensitivity in preparations 3B and 3F). Preparations $3 \mathrm{C}$ and $3 \mathrm{D}$ were obtained from ${ }^{\mathrm{V} 600 \mathrm{E}} B R A F$ mutation positive cells.

proliferation with respect to the control $(2 \mathrm{~h}$ (Fig. 6) (from the start of tetrazolium reaction)) of 29,48 , and $49 \%$ with rosiglitazone 20,30 , or $40 \mu \mathrm{M}(P=0.0001$, for all); rosiglitazone $0.1,1,5$, and $10 \mu \mathrm{M}$ did not show a significant reduction of cell activity.

The results of WST-1 assay in ANA cultured from biopsy after $48 \mathrm{~h}$ of incubation with rosiglitazone were quite similar to those obtained from FNA-ANA (data not shown).

The ${ }^{\mathrm{V} 600 \mathrm{E}}$ BRAF mutation was observed in two ATC patients. The results regarding the inhibition of proliferation by chemotherapeutic agents obtained in
biopsy-ANA cells from tumors with ${ }^{\mathrm{V} 600 \mathrm{E}} \mathrm{BRAF}$ mutation were similar to those from tumors without BRAF mutations (ANOVA).

\section{Discussion}

Here, we report the establishment of primary cell cultures from FNA in patients with ATC that could be used to test the chemosensitivity of ANA cells to different chemotherapeutic agents and TZD.

The role of surgery in ATC remains controversial. 


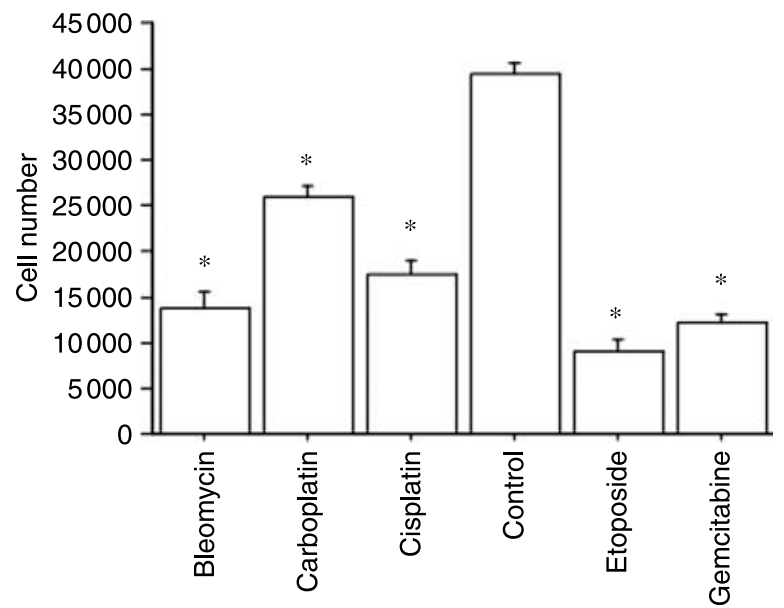

Figure 4 The results of cell counting $(2 \mathrm{~h}$ from the start of tetrazolium reaction) (mean \pm S.E.M. of all samples) in ANA cells from FNA showed a significant reduction $(P<0.001$, by ANOVA) of proliferation with respect to the control with all the tested chemotherapeutic agents (after $48 \mathrm{~h}$ of incubation).

The recently published consensus on the surgical treatment of ATC recommends complete surgical resection; that is however, justified only if postoperative morbidity rate remains low (34).

Even when surgical resection is possible, surgical treatment per se is not able to control the disease and much research is now ongoing to find new medical therapies in patients with ATC (13).

However, following an extensive review regarding the results of CT by itself or as part of a multimodal approach, until now, neither the results for doxorubicin (the most commonly used) nor for other drugs, such as cisplatin, bleomycin, etc., have been able to obtain a definitive judgement of any real effectiveness in controlling the disease (13).

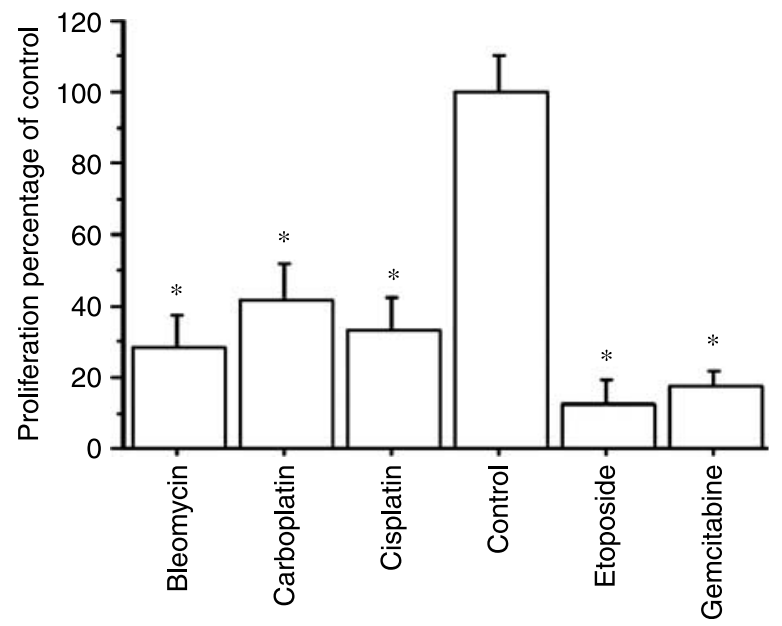

Figure 5 The results of WST-1 assay $(2 \mathrm{~h}$ from the start of tetrazolium reaction) (mean \pm S.E.M. of all samples) in ANA cells from surgical biopsy showed a significant reduction $(P<0.001$, by ANOVA) of proliferation with respect to the control with all the tested chemotherapeutic agents (after $48 \mathrm{~h}$ of incubation).

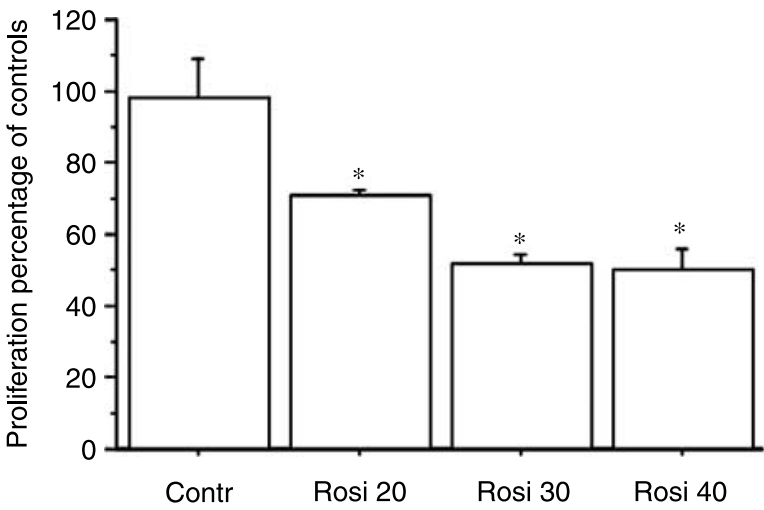

Figure 6 The results of WST-1 assay $(2 \mathrm{~h}$ from the start of tetrazolium reaction) (mean \pm S.E.M. of all samples) in ANA cells from FNA showed a reduction of proliferation with respect to the control of 29,48 and $49 \%$ with rosiglitazone (after $48 \mathrm{~h}$ of incubation) 20,30 , or $40 \mu \mathrm{M}$ (respectively; $P<0.0001$, for all).

The effect of chemotherapeutic agents has been reported for in vitro CT in ANA $(9,10)$, and recently the potential activity of paclitaxel, vinorelbine and gemcitabine in ANA has been shown. Disease orientated in vitro drug screening using human tumor cell lines has some predictive value for the activity of clinical responses (7), with a negative predictive value of 90\% (9), and might help to prevent the administration of inactive chemotherapeutics to patients.

The possibility of testing the sensitivity of ANA from each subject to different chemotherapeutic agents or other drugs could increase the effectiveness of the treatment; in fact, in vitro chemosensitivity tests are able to predict in vivo effectiveness in $60 \%$ of cases (9). There are several reasons for the discrepancy between in vitro and in vivo results: 1) the drug may be metabolized and/or inactivated in the body by different organs (liver, kidney, etc.) or in the tumor; 2) the cells may become resistant to the drug; and 3 ) the growth curve of certain tumors is very important in determining a response to chemotherapeutics. However, it is well known that a negative chemosensitivity test in vitro is associated with $90 \%$ of ineffectiveness of the $\mathrm{CT}$ in vivo (9), allowing the administration of inactive chemotherapeutics to these patients to be avoided. Moreover, this new technique will permit the evaluation of the efficacy of other drugs, different from traditional antiblastics (e.g., tyrosine kinases inhibitors), in patients with ATC in the future.

Until now, primary ANA cultures have been obtained from surgical biopsies performed for therapeutic or diagnostic procedures. Here, we report a technique to obtain cell cultures from FNA cytology in ATC. Another paper by Bravo et al. (35) reported the establishment of primary cultures by needle aspiration biopsy in only one patient. However, the reports of cutaneous needle track seeding after fine needle aspiration biopsy (FNB) in patients with thyroid cancer have been published (36, 37). FNA cytology overcomes this problem; in fact, in our 
patients we did not find any sign of needle track seeding after FNA.

The cells were submitted to CT which revealed an in vitro sensitivity to the chemotherapeutic agents used at IE50 with a higher sensitivity for etoposide and gemcitabine. The material obtained by FNA is obviously the expression of a cell population present in a limited area of the tumor, and theorically this could determine the selection of a cellular population not representative of the entire tumor. To exclude this possibility, CT was repeated under the same conditions with primary cell cultures obtained from bioptical material. The results were quite similar to those observed in FNA-ANA, excluding that FNA sampling might have brought a cell population selection.

The results of the MTT assay and of cell counting were quite similar for most of the CT used; a discrepancy was observed with carboplatin, in fact MTT assay was much more affected than cell counting. This discrepancy may be explained by the differences between the two methods, because it has already been demonstrated that there is not always a direct relationship with the cell number $(27,28)$.

Regarding the effectiveness of CT, a difference was observed among them. In fact, carboplatin reduced cell growth with respect to the control, but the cell number increased significantly with respect to the initial value (from 13000 cells per well to about 26000 cells per well), suggesting that the drug per se was not effective in inhibiting tumor growth, accordingly with clinical results. Regarding bleomycin, cisplatin, and gemcitabine, the number of cells (13 700, 17250 , and 12200 cells/well respectively) after the treatments were similar to the initial value of seeded cells, suggesting a cell cycle arrest (38-41). It could be hypothesized that if the CT had been washed out the cells would have grown again. After the treatment with etoposide about 9000 cells/well were present, less than the number seeded, suggesting a partial apoptotic effect (42); the future studies will be needed to verify this point. This last result opens the possibility to study new combinations of drugs with etoposide in this in vitro cultures and looks in the future for effective treatment for ATC.

Furthermore, the results of our study have demonstrated the anti-proliferative effect of PPAR $\gamma$ agonist rosiglitazone in FNA-ANA.

It was demonstrated that ATC cell lines express the $\operatorname{PPAR} \gamma$ gene and protein $(21,43)$. Moreover, it was found that TZD-inhibited cell growth and invasion of ATC cell lines in a dose-dependent manner. The inhibitory effect on proliferation or invasion was particularly significant in cell lines which showed higher level of the PPAR $\gamma$ gene or protein expression $(21,43,44)$. TZD mediate growth inhibition through induction of apoptosis. However, there is controversy regarding the induction of apoptosis by TZD in relation to proto-oncogene, $c$-myc, or cell-cycle inhibitor protein p27 $(16,43)$ in thyroid carcinoma. Other findings suggested that PPAR $\gamma$ agonists should induce apoptosis in ATC cell lines through the up regulation of Bax protein (21).

One of the established modes of action of the TZD is the activation of PPAR $\gamma$ (45). However, Ohta et al. (16) demonstrated no correlation between effects mediated by PPAR $\gamma$ and expression of PPAR $\gamma$ in carcinoma cells. In breast cancer cells, it has also been shown that troglitazone can repress cyclin D1 independently from PPAR $\gamma$ activation (46).

More extensive studies are needed to clarify the exact molecular mechanisms that specifically down regulate the proliferation and invasion by PPAR $\gamma$ agonists.

The results of our study have demonstrated the inhibitory effect on cell activity of TZD in FNA-ANA cells. The results were quite similar to those observed in primary cell cultures obtained from bioptical material, excluding a cell population selection, according to what was observed with chemotherapeutic agents.

Recently, it has been shown that troglitazone treatment overcomes the resistance to doxorubicin in the doxorubicin-resistant K562 human leukemia cells (47). Furthermore, it has been shown that RS5444 (a new PPAR $\gamma$ agonist) has an additive anti-proliferative activity with paclitaxel in ATC continuous cell line cultures (12). Our results showing a sensitivity of FNA-ANA cell cultures to TZD as well as to chemotherapeutic agents stimulate verifying if these drugs may have a synergic anti-proliferative effect in this type of cancer.

$B R A F$ provides crucial signals for the proliferation of thyroid carcinoma cells spontaneously harboring the ${ }^{\mathrm{V} 600 \mathrm{E}}$ BRAF mutation and, therefore, BRAF suppression might have therapeutic potential in ${ }^{\mathrm{V} 600 \mathrm{E}} B R A F$-positive thyroid cancer $(48,49)$.

Our results show that chemotherapeutic agents and TZD act both in ATC with or without ${ }^{\mathrm{V}}{ }^{\mathrm{O}}$ BRAF mutation, suggesting that their effect is mediated by other mechanisms. However, owing to the small number of patients (two with and four without BRAF mutation), further studies in larger series will be needed.

In conclusion, 1) a technique to obtain primary cell cultures from ATC from FNA-ANA cytology has been found, which allows unnecessary surgical procedures to be avoided; 2) primary cells obtained by FNA-ANA have a chemosensitivity to chemotherapeutic agents and TZD quite similar to that observed in primary cells from biopsy and 3) etoposide is highly effective in reducing cell growth, probably due to a partial apoptotic effect; this result opens the possibility to study new combinations of drugs with etoposide in these in vitro cultures and looks in the future for effective treatment for ATC. The possibility to test the chemosensitivity to different drugs in each patient is able to increase the efficacy of treatments, avoiding the administration of ineffective drugs. 


\section{References}

1 Haigh PI, Ituarte PH, Wu HS, Treseler PA, Posner MD, Quivey JM, Duh QY \& Clark OH. Completely resected anaplastic thyroid carcinoma combined with adjuvant chemotherapy and irradiation is associated with prolonged survival. Cancer 200191 2335-2342.

2 Kobayashi T, Asakawa H, Umeshita K, Takeda T, Maruyama H, Matsuzuka F \& Monden M. Treatment of 37 patients with anaplastic carcinoma of the thyroid. Head and Neck 199618 36-41.

3 Junor EJ, Paul J \& Reed NS. Anaplastic thyroid carcinoma: 91 patients treated by surgery and radiotherapy. European Journal of Surgical Oncology 199218 83-88.

4 Giuffrida D \& Gharib H. Anaplastic thyroid carcinoma: current diagnosis and treatment. Annals of Oncology 200011 1083-1089.

5 Busnardo B, Daniele O, Pelizzo MR, Mazzarotto R, Nacamulli D, Devido D, Mian C \& Girelli ME. A multimodality therapeutic approach in anaplastic thyroid carcinoma: study on 39 patients. Journal of Endocrinological Investigation 2000 23 755-761.

6 Haddad R, Mahadevan A, Posner MR \& Sullivan C. Long term survival with adjuvant carboplatin, paclitaxel, and radiation therapy in anaplastic thyroid cancer. American Journal of Clinical Oncology $2005 \mathbf{2 8} 104$.

7 Newell DR. Flasks, fibres and flanks - pre-clinical tumour models for predicting clinical antitumour activity. British Journal of Cancer 200184 1289-1290.

8 Dollner R, Granzow C, Werner JA \& Dietz A. Is there a role for chemosensitivity tests in head and neck cancer? Onkologie 2004 27 310-315.

9 Schroyens W, Tueni E, Dodion P, Bodecker R, Stoessel F \& Klastersky J. Validation of clinical predictive value of in vitro colorimetric chemosensitivity assay in head and neck cancer. European Journal of Cancer 199026 834-838.

10 Voigt W, Bulankin A, Muller T, Schoeber C, Grothey A, HoangVu C \& Schmoll HJ. Schedule-dependent antagonism of gemcitabine and cisplatin in human anaplastic thyroid cancer cell lines. Clinical Cancer Research 20006 2087-2093.

11 Ain KB, Egorin MJ \& DeSimone PA. Treatment of anaplastic thyroid carcinoma with paclitaxel: phase 2 trial using ninety-sixhour infusion. Collaborative Anaplastic Thyroid Cancer Health Intervention Trials (CATCHIT) Group. Thyroid 200010 587-594.

12 Copland JA, Marlow LA, Kurakata S, Fujiwara K, Wong AK, Kreinest PA, Williams SF, Haugen BR, Klopper JP \& Smallridge RC. Novel high-affinity PPAR $\gamma$ agonist alone and in combination with paclitaxel inhibits human anaplastic thyroid carcinoma tumor growth via p21WAF1/CIP1. Oncogene 200625 2304-2317.

13 Miccoli P, Materazzi G, Antonelli A, Panicucci E, Frustaci G \& Berti P. New trends in the treatment of undifferentiated carcinomas of the thyroid. Langenbeck's Archives of Surgery 2007 $392397-404$.

14 Grommes C, Landreth GE \& Heneka MT. Antineoplastic effects of peroxisome proliferator-activated receptor gamma agonists. Lancet Oncology 20045 419-429.

15 Antonelli A, Rotondi M, Ferrari SM, Fallahi P, Romagnani P, Franceschini SS, Serio M \& Ferrannini E. Interferon-gammainducible alpha-chemokine CXCL10 involvement in Graves' ophthalmopathy: modulation by peroxisome proliferator-activated receptor-gamma agonists. Journal of Clinical Endocrinology and Metabolism 200691 614-620.

16 Ohta K, Endo T, Haraguchi K, Hershman JM \& Onaya T. Ligands for peroxisome proliferator-activated receptor gamma inhibit growth and induce apoptosis of human papillary thyroid carcinoma cells. Journal of Clinical Endocrinology and Metabolism $2001862170-2177$.

17 Klopper JP, Hays WR, Sharma V, Baumbusch MA, Hershman JM \& Haugen BR. Retinoid X receptor-gamma and peroxisome proliferator-activated receptor-gamma expression predicts thyroid carcinoma cell response to retinoid and thiazolidinedione treatment. Molecular Cancer Therapeutics 20043 1011-1020.
18 Philips JC, Petite C, Willi JP, Buchegger F \& Meier CA. Effect of peroxisome proliferator-activated receptor gamma agonist, rosiglitazone, on dedifferentiated thyroid cancers. Nuclear Medicine Communications 200425 1183-1186.

19 Park JW, Zarnegar R, Kanauchi H, Wong MG, Hyun WC, Ginzinger DG, Lobo M, Cotter P, Duh QY \& Clark OH. Troglitazone, the peroxisome proliferator-activated receptor-gamma agonist, induces antiproliferation and redifferentiation in human thyroid cancer cell lines. Thyroid $200515222-231$.

20 Frohlich E, Machicao F \& Wahl R. Action of thiazolidinediones on differentiation, proliferation and apoptosis of normal and transformed thyrocytes in culture. Endocrine-Related Cancer 2005 12 291-303.

21 Hayashi N, Nakamori S, Hiraoka N, Tsujie M, Xundi X, Takano T, Amino N, Sakon M \& Monden M. Antitumor effects of peroxisome proliferator activate receptor gamma ligands on anaplastic thyroid carcinoma. International Journal of Oncology 200424 89-95.

22 Sherman SI. Thyroid carcinoma. Lancet 2003361 501-511.

23 Giannini R, Ugolini C, Lupi C, Proietti A, Elisei R, Salvatore G, Berti P, Materazzi G, Miccoli P, Santoro M \& Basolo F. The heterogeneous distribution of BRAF mutation supports the independent clonal origin of distinct tumor foci in multifocal papillary thyroid carcinoma. Journal of Clinical Endocrinology and Metabolism 200792 3511-3516.

24 Salvatore G, Giannini R, Faviana P, Caleo A, Migliaccio I, Fagin JA, Nikiforov YE, Troncone G, Palombini L, Basolo F \& Santoro M. Analysis of BRAF point mutation and RET/PTC rearrangement refines the fine-needle aspiration diagnosis of papillary thyroid carcinoma. Journal of Clinical Endocrinology and Metabolism 2004 89 5175-5180.

25 Basolo F, Fiore L, Calvo S, Falcone V, Conaldi PG, Fontanini G, Caligo AM, Merlo G, Gluzman Y \& Toniolo A. Defective interleukin six expression and responsiveness in human mammary cells transformed by an adeno 5/SV40 hybrid virus. British Journal of Cancer 199673 1356-1361.

26 Berridge MV, Herst PM \& Tan AS. Tetrazolium dyes as tools in cell biology: new insights into their cellular reduction. Biotechnology Annual Review 200511 127-152.

27 Gutiérrez-Cañas I, Rodríguez-Henche N, Bolaños O, Carmena MJ, Prieto JC \& Juarranz MG. VIP and PACAP are autocrine factors that protect the androgen-independent prostate cancer cell line PC-3 from apoptosis induced by serum withdrawal. British Journal of Pharmacology 2003139 1050-1058.

28 Kamikubo Y, Takaori-Kondo A, Uchiyama T \& Hori T. Inhibition of cell growth by conditional expression of $\mathrm{kpm}$, a human homologue of Drosophila warts/lats tumor suppressor. Journal of Biological Chemistry 2003278 17609-17614.

29 Gillman G. The Pharmacological Basis of Therapeutics New York: McGraw-Hill, 2005.

30 Li W, Lam MS, Birkeland A, Riffel A, Montana L, Sullivan ME \& Post JM. Cell-based assays for profiling activity and safety properties of cancer drugs. Journal of Pharmacological and Toxicological Methods $2006 \mathbf{5 4} 313-319$.

31 Fridborg H, Nygren P \& Larsson R. Relationship between pharmacokinetic parameters in patients and cytotoxicity in vitro of standard and investigational anticancer drugs. Anticancer Drugs $1995664-69$.

32 Abbruzzese JL, Grunewald R, Weeks EA, Gravel D, Adams T, Nowak B, Mineishi S, Tarassoff P, Satterlee W Raber MN et al. A phase I clinical, plasma, and cellular pharmacology study of gemcitabine. Journal of Clinical Oncology 19919 491-498.

33 Millward MJ, Newell DR, Mummaneni V, Igwemezie LN, Balmanno K, Charlton CJ, Gumbrell L, Lind MJ, Chapman F Proctor $\mathrm{M}$ et al. Phase I and pharmacokinetic study of a watersoluble etoposide prodrug, etoposide phosphate (BMY-40481). European Journal of Cancer 1995 31A 2409-2411.

34 Force TCT. AACE/AAES medical/surgical guidelines for clinical practice: management of thyroid carcinoma. American Association of Clinical Endocrinologists. American College of Endocrinology. Endocrine Practice 20017 202-220. 
35 Bravo SB, García-Rendueles ME, Seoane R, Dosil V, CameselleTeijeiro J, López-Lázaro L, Zalvide J, Barreiro F, Pombo CM \& Alvarez CV. Plitidepsin has a cytostatic effect in human undifferentiated (anaplastic) thyroid carcinoma. Clinical Cancer Research 200511 7664-7673.

36 Karwowski JK, Nowels KW, McDougall IR \& Weigel RJ. Needle track seeding of papillary thyroid carcinoma from fine needle aspiration biopsy. A case report. Acta Cytologica $2002 \mathbf{4 6}$ 591-595.

37 Uchida N, Suda T, Inoue T, Fujiwara Y \& Ishiguro K. Needle track dissemination of follicular thyroid carcinoma following fine-needle aspiration biopsy: report of a case. Surgery Today 200737 34-37.

$38 \mathrm{Wu}$ M, Zhang Z \& Che W. Suppression of a DNA base excision repair gene, hOGG1, increases bleomycin sensitivity of human lung cancer cell line. Toxicology and Applied Pharmacology 2008 228 395-402.

39 Pani E, Stojic L, El-Shemerly M, Jiricny J \& Ferrari S. Mismatch repair status and the response of human cells to cisplatin. Cell Cycle 20076 1796-1802.

40 Voigt W, Bulankin A, Müller T, Schoeber C, Grothey A, HoangVu C \& Schmoll HJ. Schedule-dependent antagonism of gemcitabine and cisplatin in human anaplastic thyroid cancer cell lines. Clinical Cancer Research 20006 2087-2093.

41 Kotchetkov R, Gröschel B, Gmeiner WH, Krivtchik AA, Trump E, Bitoova M, Cinatl J, Kornhuber B \& Cinatl J. Antineoplastic activity of a novel multimeric gemcitabine-monophosphate prodrug against thyroid cancer cells in vitro. Anticancer Research $2000202915-2922$.

42 Lomonaco SL, Kahana S, Blass M, Brody Y, Okhrimenko H, Xiang C, Finniss S, Blumberg PM, Lee HK \& Brodie C. Phosphorylation of PKCdelta on distinct tyrosine residues induces sustained activation of Erk1/2 via downregulation of MKP-1: role in the apoptotic effect of etoposide. Journal of Biological Chemistry $200828317731-17739$.
43 Martelli ML, Iuliano R, Le Pera I, Sama I, Monaco C, Cammarota S, Kroll T, Chiariotti L, Santoro M \& Fusco A. Inhibitory effects of peroxisome poliferator-activated receptor gamma on thyroid carcinoma cell growth. Journal of Clinical Endocrinology and Metabolism 200287 4728-4735.

44 Aiello A, Pandini G, Frasca F, Conte E, Murabito A, Sacco A, Genua M, Vigneri R \& Belfiore A. Peroxisomal proliferatoractivated receptor-gamma agonists induce partial reversion of epithelial-mesenchymal transition in anaplastic thyroid cancer cells. Endocrinology $20061474463-4475$.

45 Otto C, Lehrke M \& Goke B. Novel insulin sensitizers: pharmacogenomic aspects. Pharmacogenomics 20023 99-116.

46 Huang JW, Shiau CW, Yang YT, Kulp SK, Chen KF, Brueggemeier RW, Shapiro CL \& Chen CS. Peroxisome proliferator-activated receptor gamma-independent ablation of cyclin D1 by thiazolidinediones and their derivatives in breast cancer cells. Molecular Pharmacology 2005 67 1342-1348.

47 Davies GF, Roesler WJ, Juurlink BH \& Harkness TA. Troglitazone overcomes doxorubicin-resistance in resistant K562 leukemia cells. Leukemia and Lymphoma 200546 1199-1206.

48 Salvatore G, De Falco V, Salerno P, Nappi TC, Pepe S, Troncone G, Carlomagno F, Melillo RM, Wilhelm SM \& Santoro M. BRAF is a therapeutic target in aggressive thyroid carcinoma. Clinical Cancer Research $2006121623-1629$.

49 Begum S, Rosenbaum E, Henrique R, Cohen Y, Sidransky D \& Westra WH. BRAF mutations in anaplastic thyroid carcinoma: implications for tumor origin, diagnosis and treatment. Modern Pathology 200417 1359-1363.

Received 5 June 2008

Accepted 11 June 2008 